\title{
The Necessity and Ways to Develop the methodology of Management Decision Making Support for Innovative Development of Mining Regions in Russia
}

\author{
Lazarenko Sergey N. ${ }^{\mathrm{a}}$, Dubov Georgiy M. ${ }^{\mathrm{b}}$, \\ Zykov Andrei V.', Shirokolobova Anastasia G. ${ }^{\mathrm{d}}$ \\ T. F. Gorbachev Kuzbass State Technical University, \\ Kemerovo, Russian Federation. \\ as.lazarenko2009@mail.ru; ${ }^{b}$ nikokem@ @ail.ru; ${ }^{\mathrm{c}}$ kuztpp@bk.ru; ${ }^{\mathrm{d}}$ nastja_shirokolo@ rambler.ru
}

\begin{abstract}
The paper describes the development of a complex method of decision making support for the objectives of the Russian Federation innovative development with regard to the specific conditions of mining regions of the country. The extremely large amount of unstructured and poorly structured information in the field of mining industry makes it very difficult formanagers and industry experts make effective decisions in the aspects of safety, accidents, efficiencyand innovative management. The new methodology makes provisions for wider range of information and equipment measures fordecision making supportfor innovative development of mining regions of Russia. The theoretical basis of this study is Data Mining paradigm, which is based on the concept of samples (patterns) reflecting fragments of the multifaceted relations of the incoming data. A special case of the Data Mining is the Text Miningtechnology, which is implemented in decision support systems (DSS). When applied to a wide range of generated branch information, this technology allows creating knowledge bases in the field of mining production management, which increase the efficiency of managers' decision making in the public and commercial branches of industry.
\end{abstract}

Keywords - decision making support, mining region, innovative development, management solutions, information technology.

\section{INTRODUCTION}

Firstly, the systems and methods for decision making support in their modern sense were developed in the USA in the early 1970 s $[15,16]$. The first national researches in this field appeared in the middle of 1980s [9].

Currently, there are many types of decision making support systems as well as methods of their classification: for example, they are classified by the usage purposes, the field of possible applications, the method of variables'evaluation, etc. The requirements to such kind of systems are constantly increasing, due to the demand increase in correct data, even if data is of probabilistic nature, as well as due to the time limits stiffening toquery mode and data usage, received from noncomputerized sources.
It can be noted that the technology of decision making support was not used up to now for the integrated regional (branch)management with the help of intelligent digital cloud, with the access to the decision makers (DM) of different hierarchy and subordination, though such systems are applied to urban management [ 4, 6], multilevel companies [8] and investments [17].

Today, there is a requirement to develop a new complex methodology for decision making support, which allows, with significantly greaterefficiency and speed than before, to identify those areas of research and those destinations of investments which can actively stimulate the development of the real sector of the Russian economy, and specifically can stimulate the innovative development of mining regions, the specific features of which are generation and reception of a large volume of unstructured information.

"Fresh" example of the need to support authorized people to make informed decisions is the situation in the coal industry after the tragic case of the 36 miners' death at the mine "Severnaya" in February 2016. The Russian government, as well as the heads of the coal regions understood the requirement to close a number of dangerous coal mines. The solution had to be taken on the basis of the available volume of poorly structured information of specific mine technical and social nature. It can be argued that in this situation (as, indeed, and in many other similar cases) decision makers could be helpedby the amount of complete, objective and structured information to make the optimal and highly informed decision;the developed by the authors methodology will provide the principlesof complete, objective and structured information.

According to the authors, the most appropriate and effective theoretical basis for the planned researcheswill be the Data Miningparadigm, which is based on the concept of samples (patterns), reflecting fragments of the multifaceted relations of the incoming data as well as informative cognitive Text Miningtechnology. The possibilities of such approach, 
previously used in business [11] and scientific studies, have no any examples of applications in the field of regional (industry) management. In the process of solving the taskit is expected through the usage of Data Mining concepts and Text Mining technology to develop the effective methodology of objective and reliable assessment of the executability degree of new technological solutions and technologiesin mining industrial regions of the Russian Federation.

The purpose of the research is to explore new opportunities for generation and utilization of management knowledge, which the DSS usage creates for complexbranchof regional management in the mining industry.

\section{OBJECT OF STUDY}

The idea of development and utilization of the fundamental researches results of the problem of decision making support by decision makers (DM) and by analytics, operating with large amount of unstructured and poorly structured data sources, is studied.

Currently, there is no coherent theory of decision making based on the automated analysis of information flows, generated in the mining region (sector). The project explores the possibility of creating an integrated model of industry knowledge, based on the techniques and methods of intellectual analysis of information flows (Text Mining). Mining industry is a complete system that includes a plurality of components interconnected. It is actually an industrialcomplex, research and educational institutions, design institutes, companies, manufacturers and suppliers of equipment and technology, authorities and technical supervision. The most important attributes of this system are the cognitive and creative abilities of a man, which cannot be neglected in such studies [7].All these components of the study object are the generators and recipients of the industry branch information and they are connected by complex information flows, which affect the industry in general in the management aspects: innovation development, efficiency, investment, ecology, security.

\section{METHODS}

In our research the mining region (the mining industry) is considered as a system that had appeared andnow is serving not only as the sum of the components, but it is functioning and developing as a whole unit. The networking and interinfluences,specific to the object, have an impact on each component, it provesthe integral nature of the object of research;outside these networking and interinfluences a component, as a mechanical part only, (an industrial complex, scientific and educational institutions, public authorities and supervision,producers/suppliers of equipment and technology) cannot be understood and studied [2]. This means that the desired patterns of effective decisions are not located in separate components of the industry, and permeate the mining industry as a whole. Their determination, "pushing" in the area of knowledge is possible if complex of interregional (intrasect oral) information flows in the places of their generation, reception and circulation will be studied by means of intellectual analysis of texts $[2,3]$.

Information environment of the mining region with its study by means of Text Mining technology produces a lot of non-obvious parameters of its processes and structural configurations, on the basis of which the most important parameters for the synthesis of complex model of effective decisions for sets / subsets of management situations are distinguished.

The following methods and approaches are used $[1,13$, 14], having substantive author interpretation (Fig. 1).

Text Mining technology possibilities are associated with extraction from the text of its specific non obvious elements or properties. Other features of the technology allowincluding documents from the information set to the categories according the classification scheme.

There are the following elements of the Text Mining technology:

\section{CREATION OF A MODEL OF KNOWLEDGE BASE OF TECHNICAL DECISIONS BASED}

ON THEIR META DESCRIPTIONS AND ONTOLOGY

2. COMPUTER MODELING OF PATTERNS OF EFFECTIVE DECISIONS FOR SETS / SUBSETS OF MANAGEMENT SITUATIONS

3. METHODOLOGY OF CREATION OF INDUSTRY BASED INFORMATION-RETRIEVAL THESAURUSES

4. COGNITIVE TEXT MINING TECHNOLOGY, ALLOWING TO FORM THE SCHEME OF PREVIOUSLY UNKNOWN RELATIONS AND CORRELATIONS IN TEXT DATA, WITH DETERMINATION OF THE MOST SIGNIFICANT ATTRIBUTES

Fig. 1.Methods and approaches, having substantive author interpretation 
- Classification. In text classification the statistics methods are used to place the documents in certain categories;

- Clustering. Clustering forms compact clusters (collection) of objects with similar properties. The system automatically selects the characteristics and distributes the objects by subgroups. Clustering is usually preceded by a classification, as it allows offering a group of objects;

- Construction of semantic networks (analysis of links), which allowsto set descriptors (key phrase) in a document for the navigation purpose;

- Extraction of facts, concepts (featureextraction). It is used to produce new facts from the text in order to improve the classification, search and clustering;

\section{- Summarization;}

- Query answer;

- Thematic Indexing;

- Keywordsearching.

The research process is divided into the following stages, which are connected with each other in series (Fig. 2).

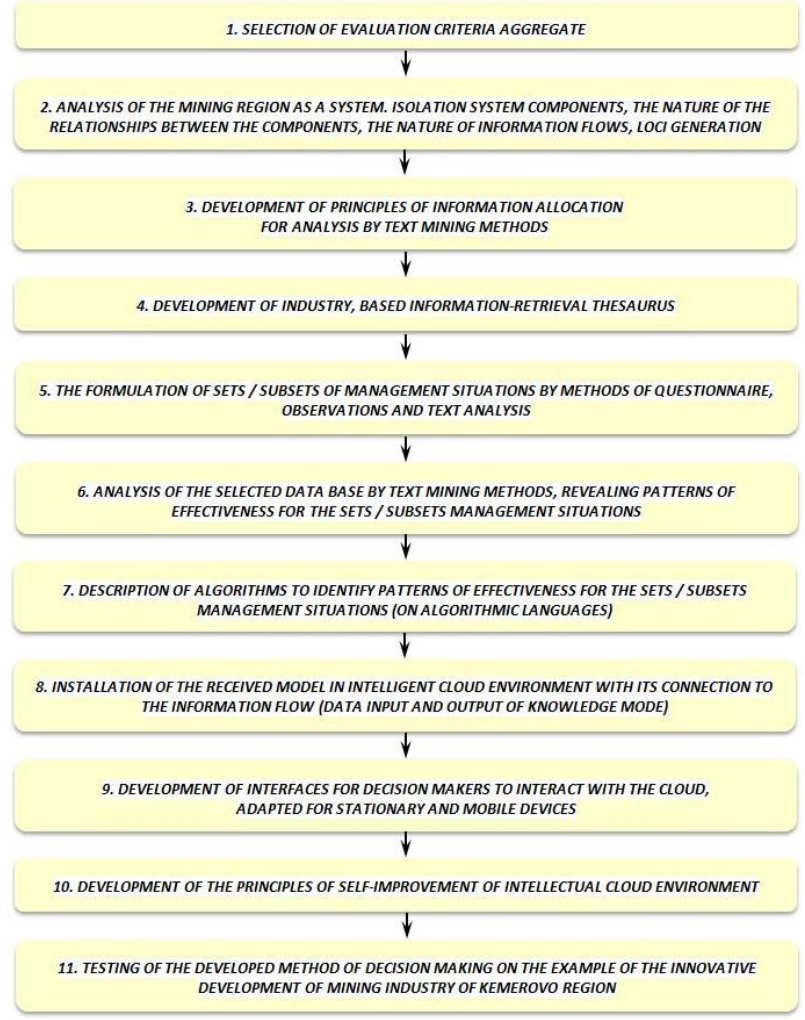

Fig. 2.Stages of research process

\section{RESULTS AND DISCUSSION}

The research solves a fundamental interdisciplinary problem of construction of the decision making theory in the innovative development process of the mining region on the basis of complex algorithmic model of effective decisions, applicable for a wide range of industry applications. During the research this model is formed by numerous iterations
[5,12], made on industry data baseby means of text mining technology (Text Mining), followed by a synthesis of knowledge gained in various fields. In the process of iteration effectiveness patterns for sets / subsets of management situations will be found. The next stage is the model selfimprovement and brining to formal status, which can be described by algorithmic languages. In this state, the model can be installed in intelligent cloud digital environment with access for decision makersto test and to operation it.

Installation of the model into intelligent cloud environment with its connection to the flows of regional and sector information leads to positive effects: reduce the chaos level [10] during the initial processing of information, time reduction to make decisions, the decision quality rise in the aspects of innovation development, efficiency, investment, ecology and security (the latter aspect is especially relevant for mining regions).

\section{CONCLUSION}

The authors believe that the above studies, despite the fact that they have not been completed, can now serve as a valuable methodological tool for the researchers and experts, who intend to apply or to explore the possibilities of the decision support systems applicationin the area of branch managementand industrial clusters.

The following results are supposed to be received inresult:

1. The set of algorithms of complex model of effective decisions in the innovative development conditions of mining regions for a wide variety of management situations.

\section{Sector information-retrieval thesaurus.}

3. Complex model of effective decisions, installed in the cloud digital environment with an option of "self study" in the process of exploitation.

4. Guidelines for formulating queries to the system for decision makers with the dictionary for sets / subsets of management situations in the mining industry.

5. The software is on the smart cloud technology platform with an intuitive interface for interaction between decision makers, adapted for stationary and mobile devices (uniqueness of decision- intelligentcloud system operates outside a particular company / institution, it creates a positive synergy effect for the region and the industry in general).

\section{REFERENCES}

[1] Abakumov O. Clustering in text mining application // New information technologies in automated systems. 2010. \#13. P.128-129

[2] Blauberg I.V. The problem of integrity and systematic approach. - M : Editorial URSS, 1997.- 448 p.

[3] Gukhman V.B. Philosophy of information approach: monograph. - Tver: Publishing house of Tver State Technical University Press, 2000. - 167 p. 
[4] Grebenyuk G.G. Features of automated systems development of computer support for decision making in management tasks in city life support // Problems of management. \#5 2006. P. 44-48.

[5] Karelin V.P. Intelligent technologies and artificial intelligence systems for decision making support // Bulletin of Taganrog Institute of Management and Economics. 2011. \#2 P.79-84.

[6] Kochegurova E.A., Martynov U.A. Optimizing of public transport routing when creating an automated support system // Proceedings of the TPU. 2013. \#5 P.79-84

[7] Kravchenko U.A. Assessment of the user cognitive activity in decision making support systems // Proceedings of SFU. Technical Science. 2009. \#4 P.113-117.

[8] Krivodubskiy O.A., Chikunov P.A. Analysis of modern methods of constructing of decision support systems for multilevel enterprise // Philosophical problems of information technologies and cyberspace. 2014. \#2 P.20-40.

[9] Larichev O.I., Petrovskiy A.V. Decision making support systems. Current status and prospects of their development // Results of science and technology. TechnicalCybernetics. - V.21. M .: VINITI, 1987, P. 131164.
[10] Prigogine I.R., Stengers I. Order out of chaos. The new dialogue of man with nature. - M .: Progress, 1986. -432 p.

[11] Sorokoletov P.V. Construction of intelligencesystems for decision making support systems // Proceedings of the SFU. Technical Science. 2009. \#4 P.117-124.

[12] Terelyanskyi, P.V.Decision making support systems. Experience in projecting: monograph. Volgograd : VSTU, 2009. - 127 p.

[13] Hayrova N.F., Sharonova N.V. Model of automation information-search thesaurus formation of digital library // Electronics and Informatics. 2002. \#4 (21) P.117-119.

[14] Chernyakhovskaya L.R., Shkundina R.A., Nugaeva K. Ontological approach to the decision support systems development // Bulletin of USATU. 2006. \#4 P.68-77.

[15] Alter S. L. Decision support systems: current practice and continuing challenges. Reading, Mass.: Addison-Wesley Pub., 1980.

[16] Bonczek R.H., Holsapple C., Whinston A.B. Foundations of Decision Support Systems.-NewYork: AcademicPress, 1981.

[17] Fieldera A., Panaousisb E., Malacariac P., Hankina C., Smeraldic F. Decision support approaches for cyber security investment // Decision Support Systems. 2016. Vol. 86. P. 13-23. 